\title{
Am I being watched? The role of researcher presence on toddlers' behaviour during 'everyday' pain experiences: A pilot study
}

\author{
Line Caes, University of Stirling \\ Grace O'Sullivan, National University of Ireland, Galway \\ Brian McGuire, National University of Ireland, Galway \\ Michelle Roche, National University of Ireland, Galway
}

\begin{abstract}
Objective: Paediatric research on 'everyday' pain experiences is sparse, stemming from a lack of appropriate methodologies. We explored the feasibility of two methodologies for conducting naturalistic observations of 'everyday' pains within family's homes, against an established methodology for day-care observations.
\end{abstract}

Design: Within family homes, video-cameras recorded a typical morning or afternoon (maximum three hours), either with, or without researcher presence. To compare feasibility, children in day-care were observed by researchers for three hours without video-recording.

Outcome measures: logistics of observation, child pain behaviours, caregiver responses to child pain.

Results: Thirteen children $\left(\mathrm{M}_{\mathrm{age}}=45.4\right.$ months $)$ were recorded at home, experiencing 14 pain events. Researcher presence increased child distress intensity, but reduced the number of pain events compared to sessions without a researcher. Thirty-two children $\left(\mathrm{M}_{\mathrm{age}}=48.4\right.$ months $)$ were observed in day-care, experiencing 44 pain events. Children experiencing pain events in day-care exhibited decreased distress and lower personal control than those observed at home. Across all conditions, caregivers engaged mostly in physical comfort. Researcher estimates of child pain were highest if scored while present in the home.

Conclusions: Observing everyday pain events within the child's natural environment is feasible and may provide insight into the social context of childhood pain experiences.

Keywords: paediatric; home observation; video-recording; day-care; non-clinical pain 


\section{Introduction}

Pain is an unavoidable experience in childhood, with frequent experiences of falling or scraped knees (Perquin, Hazebroek-Kampschreur et al., 2000). This is a necessary learning experience, and children mainly depend upon their parents for help and care in such situations (Hadjistavropoulos, Craig et al., 2011; Noel, Chambers et al., 2018; Palermo, Valrie, \& Karlson, 2014). Common support strategies are to provide physical and verbal comfort to soothe their pain (e.g., Blount, Devine et al., 2008; Brown, De Young et al., 2018; Claar, Simons, \& Logan, 2008), or to distract the child with toys or other novelties (e.g., Kleiber \& Harper, 1999; MacLaren \& Cohen, 2005; Manimala, Blount, \& Cohen, 2000; Noel et al., 2018; Weiss, Dahlquist, \& Wohlheiter, 2011). Debate is ongoing regarding the most appropriate caregiver response to children experiencing acute pain, with current evidence favouring the use of distraction (Birnie, Chambers et al., 2015; Chambers, Taddio et al., 2009). However, a limitation of the existing evidence is the disproportionate focus on pain experienced within medical settings (e.g., vaccinations) or pains which may indicate an underlying medical problem (e.g., headaches or abdominal pains). Spontaneous pain experiences are a common part of childhood: abdominal pains have an estimated prevalence of $10-20 \%$ in school-aged children worldwide (Chitkara, Rawat, \& Talley, 2005; Perquin et al., 2000). Vaccinations are more common: infants in the UK and Ireland receive over a dozen scheduled vaccinations within the first twelve months, with further inoculations at pre-school and school ages, providing a wealth of data on pain interactions during vaccinations (Blount, Bachanas et al., 1992; Blount et al., 2008; HSE, 2016; Lisi, Campbell et al., 2013; Manimala et al., 2000; NHS, 2016; Pillai Riddell, Taddio et al., 2015). Yet, 'everyday’ pains (bumps, scrapes, etc.) are the most frequent of all, especially in toddlers who may experience minor pains multiple times per day (Fearon, McGrath, \& Achat, 1996). These typically produce mild, brief distress but usually do not require intervention beyond reassurance (von Baeyer, Baskerville, \& McGrath, 1998). 
Despite potentially being a lesser cause for concern, 'everyday' pain experiences represent a model for children to learn pain management skills from those in their social environment, including parents (Blount et al., 1992; Boerner, 2017; Boerner, Chambers et al., 2017; Brown et al., 2018), day-care staff (Fearon et al., 1996; Gilbert-MacLeod, Craig et al., 2000; von Baeyer et al., 1998), and other children (Goubert, Vlaeyen et al., 2011; Zeman \& Garber, 1996). In turn, as pain skills develop, the child's response to minor pain events may influence those around them; i.e., if the child is managing adequately, caregivers may be less likely to intervene or attempt to control the situation (Caes, Vervoort et al., 2012; Fearon et al., 1996; Goubert, Vervoort et al., 2008; von Baeyer et al., 1998). As minor everyday pain experiences may impact on how a child develops pain responses, it is crucial to gain a better understanding of childcaregiver reciprocal influences during these painful situations (Blount et al., 2008; Kochanska \& Aksan, 2004), and the development of pain management skills in early years (GilbertMacLeod et al., 2000).

There is a paucity of paediatric research on everyday pains: Noel and colleagues found that just three studies in the previous two decades had examined everyday pain in children aged 2-7 years old (Noel et al., 2018). The limited coverage of everyday pain within the literature could stem from the spontaneity of such events, the inability to control extraneous factors, and a lack of rigorous methodologies (or difficulties with adapting existing methodologies) to capture such experiences adequately (Christensen, 2007; Fearon et al., 1996; von Baeyer et al., 1998). Existing studies have relied on self-reports from parents, which feature subjective elements such as incomplete recall of events or bias to increase social desirability; i.e., only reporting use of 'good' parenting methods (Morsbach \& Prinz, 2006). Other studies have gathered self-reports from children; however, many pain assessment tools are unsuitable for younger children (3-4 years), who cannot distinguish between items reliably (Emmott, West et al., 2017; Tomlinson, von Baeyer et al., 2010; von Baeyer, 2017; von Baeyer \& Spagrud, 2007). 
Observational studies within day-care centres can objectively capture large quantities of pain events, but at a cost: logistical barriers to video-recording events, including data protection and child anonymity considerations; and practical difficulties with moving equipment and ensuring that every child is clearly visible on recordings, to gather adequate data from pain events; hence, 'in-the-moment' coding is common, though potentially less reliable. Furthermore, as parents are usually not present in day-care settings, key interactions and learning opportunities may be missed (Hadjistavropoulos et al., 2011; Kochanska \& Aksan, 2004; Noel et al., 2018). Given these methodological challenges to gaining insight into children's everyday pain experiences, it is imperative to develop and implement a systematic approach to the study of everyday experiences to facilitate the expansion of our understanding in this domain.

The aim of this pilot study was to explore the feasibility of conducting naturalistic observations of pre-schoolers' everyday pain experiences within their home; as such, no hypotheses were defined a priori. Based on previous observational procedures (Campos, Graesch et al., 2009; Fearon et al., 1996; Gilbert-MacLeod et al., 2000), this pilot study firstly intended to determine the feasibility of two methods for home-based observation of everyday pain experiences in pre-schoolers by video-recording parent-child interactions during a typical morning or afternoon at home. To establish the viability of these home-based methods, they were compared with an established method of observation, within a day-care setting (Fearon et al., 1996). Specifically, the goals were to explore:

1. whether researcher surveillance during home-based observations is necessary, and/or creates feelings of intrusion in parents and children;

2. whether a 3-hour timeframe is sufficient to capture at least one painful event;

3. whether observation in the home environment captures different pain experiences to a day-care environment 


\section{Methods}

Observational studies of 'everyday' pains are challenging: as spontaneous occurrences, there is no guarantee of capturing them within laboratory settings, but there is a lack of suitable methodologies for studying them in natural settings (Christensen, 2007; Fearon et al., 1996). Such studies often face difficulties in recruitment and finding adequate tools, including issues related to reliability of existing scales or developing new measures to capture the events more accurately, such as more detailed scales or the use of video-recording (Noel et al., 2018), and in maintaining validity across different contexts, as pain experiences in one setting may not translate elsewhere (Gilbert-MacLeod et al., 2000). These challenges informed the design of the current study, to combine objective (recordings) and subjective data (face scales and pain rating scales), and to preserve natural behaviours through minor restrictions on activities (e.g., no TV watching), based on previous observational studies (Campos et al., 2009; GilbertMacLeod et al., 2000). A small sample $(\mathrm{N}=12)$ was chosen, to identify challenges with recruitment for home-based research, and potential logistical or equipment difficulties, while still meeting sample guidelines for pilot studies (Hertzog, 2008). Furthermore, to reduce novelty and preserve the natural environment, researchers in each setting were introduced to the children with the explanation that they would be doing homework during the session and should not be disturbed. In the event that children initiated contact, the researcher would politely explain that they were not allowed to play as they had to do their homework (Fearon et al., 1996); this procedure did not need to be implemented ultimately, as children generally went about playing and did not appear interested in interacting with the researcher beyond initial introductions.

\section{Procedures for home-based observations}


For home-recordings, families with a child between 3 and 5 years old were recruited at local child-care centres and play-groups, through posters and flyers circulated at each location. Interested parents contacted the research team via phone-call or email, and a member of the research team would complete eligibility screening. Eligibility criteria included: at least one child aged 3-5 years; parent and child both generally pain-free and healthy; parent able to read and write in English. Once eligibility was confirmed, the family could choose a time-slot for their recording.

Participating families were recorded within their own home over a 3-hour observation period (usually in the morning or afternoon). This duration was chosen in line with previous studies in day-care settings (Fearon et al., 1996; Gilbert-MacLeod et al., 2000; von Baeyer et al., 1998). Families were randomly assigned to one of two methodologies: half of the families completed the observation period while a member of the research team remained within their home for additional note-taking on the interactions between parent and child ('Researcher Present Home'). For the other families, the researcher did not remain present during the observation period; after setting up the camera equipment and collecting consent sheets, they returned only at the end of the session ('Researcher Not Present Home'). Independent of the assigned methodology, two cameras were set up to capture two rooms and all events during recording. To capture natural parent-child interactions some minor restrictions were placed on the families, following previous observational research: parents should remain nearby in case a pain event occurred; no visitors or outgoing phone calls were allowed during the recording; and TV watching should be kept to a minimum to encourage active play (Campos et al., 2009; Gilbert-MacLeod et al., 2000).

Before the recording started, consent and assent were gathered from parent and child, and special care was taken to ensure that the child understood the assent process, using verbal exercises to emphasise their right to say no (e.g., 'If I asked you to eat a bug, do you have to 
do it?' or 'Will your mum or dad be upset if you don't want to take part?') (Weiss et al., 2011). Following this, the three-hour recording began. Pain events were operationalised as being any event in which (1) the child appeared to be in minor discomfort, or (2) expressed pain or exhibited pain-related behaviours (such as crying, anger, or protective motions, such as rubbing the affected area). Each time a pain event occurred, the child was asked by the parent (or the researcher, if present) to rate their experienced level of pain using the Faces Pain Scale-Revised (FPS-R) (Hicks, von Baeyer et al., 2001) (see Materials). Parents provided a proxy rating for their child's pain using the FPS-R, and rated their own distress on a numeric rating scale (Caes, Vervoort et al., 2011). Researchers completed the Dalhousie Everyday Pain scale (DEPS) for each pain event, detailing the context of the event and the responses of the child and caregiver(s) involved (Fearon et al., 1996). In the 'Researcher Present Home' condition, DEPS was completed either during or immediately after each pain event; in the 'Researcher Not Present Home' condition, DEPS was completed afterwards by one member of the research team while watching the video-recordings. At the end of the recording, all parents were asked to complete an anonymous survey detailing feedback on their experience of participation in the study (see Results).

\section{Procedures for day-care observations}

The 'Researcher Present Day-care' observations took place at the University of Stirling, Division of Psychology Kindergarten. During enrolment in this day-care, parents sign a general consent form for their child to participate in research. Before the start of this study, parents received informed consent sheets and had two weeks to opt out. Five 3-hour observation periods were conducted over a three-week period. Each observation consisted of covert observation via one-way screens during morning drop-off (30 minutes); overt recording during the morning ( 2 hours); and covert observation at pick-up time (30 minutes). During observations, children carried out standard activities such as creating art, free play, reading, 
etc. As in the home, the researcher was careful to not initiate contact directly with the children and would politely decline if children attempted to initiate contact. For each pain event that occurred, the researcher would ask the child to rate their pain using the Faces Pain ScaleRevised (FPS-R) (Hicks et al., 2001) before completing the Dalhousie pain scale themselves (Fearon et al., 1996). Caregivers were not asked to complete either pain scale.

\section{Materials}

\section{During observation}

\section{Faces Pain Scale-Revised (FPS-R)}

The child completed the FPS-R immediately after each pain event that occurred. The FPS-R comprised six faces, showing increasing amounts of pain, scored from 0-10 in 2-pt intervals. Children were asked to indicate which face represented the level of pain they were experiencing at that moment (Hicks et al., 2001). As one of the leading scales for paediatric self-report, the FPS-R has been validated extensively in preschool populations and can be administered without extensive training, making it suitable for teachers or parents (Hicks et al., 2001; von Baeyer, 2017). In the home observations, parents also used the FPS-R to give a proxy rating of the level of pain they thought their child was experiencing.

\section{Dalhousie Everyday Pain Scale}

The Dalhousie scale (DEPS; Fearon et al., 1996) was completed by the researcher for each pain event that occurred. This scale contained 15 items relating to the context of a pain situation: 1 ) location of the incident (one item); 2) description of the incident (three items: bodily location of pain, who/what caused the pain, researcher perception of pain severity); 3) physical and behavioural context (four items: activity level, emotional tone, level of personal control (defined as "the amount of personal control the child was exercising immediately prior to the incident" (Fearon et al., 1996)), and number of people involved); 4) child's response to the 
incident (six items: intensity of anger, direction of anger (e.g., to self or another), intensity of distress, duration of distress, nature of any protective behaviours (e.g., holding or favouring the injured area), and social response ('withdrawn', 'neutral', or 'help-seeking' from others) and 5) adult's response (one item). Body location, cause of pain, protective behaviour, social response, and adult response were recorded using nominal scales, and answers were mutuallyexclusive (researchers are instructed to list the most prominent answer, should multiple answers be applicable; e.g., location of injury) (Fearon et al., 1996). Activity level, number of participants, perceived severity, intensity of distress, and intensity of anger were recorded using ordinal scales (e.g., 0='Low/no'; 4 (or 5)='High/a lot'), and level of personal control was rated inversely (1=high control; 5=low control) (Fearon et al., 1996). Duration of distress was measured with a stopwatch. The DEPS is the current standard for assessing everyday pain experiences in preschool children, having been used in multiple studies, and exhibits good validity and inter-rater reliability for young ages (3-7 years) (Fearon et al., 1996; von Baeyer et al., 1998).

For use within the day-care, minor modifications were made to the Dalhousie scale: first, within the item Adult Response, the measure 'first aid' was replaced by 'conflict negotiation', as pain events within the day-care often result from fighting between 2 or more children, but this was not always relevant within the home-based recordings where there was often only one child. Finally, the original item Protective Behaviours and its measures $(0-4$ : none, holding, favouring, reduction of activity) was eliminated. Within the day-care, our primary interest lay in social responses to pain events, rather than protective behaviours, which were not central to this research question.

\section{Post-observation}

\section{Research participation evaluation survey}


As this study aimed to assess the feasibility of video-recording to capture natural interactions, it was crucial to gather feedback from those participating in the home-recording sessions. All participating parents completed an anonymous survey to give feedback on the study, detailing (a) their overall experience during participation, e.g., level of comfort, feelings of intrusion, and level of satisfaction with the duration of recording; (b) whether their behaviour or that of their child had changed due to the presence of recording equipment; (c) any negative experiences during their participation; and (d) any other issues that arose during the session, along with any additional comments they wished to make (Appendix).

\section{Data Analysis}

Demographic data and quantitative survey responses were analysed using descriptive tests in SPSS 24.0 (IBM Corp, Armonk, NY). As one of the primary aims was to determine whether home-based recording methodologies were feasible, and comparable to an existing methodology, one key characterisation was whether pain experiences were similar across the three conditions: several Dalhousie variables were compared using one-way ANOVA: distress intensity, distress duration, social response, adult response, level of personal control, and observer pain estimates; with Fisher's post-hoc tests when appropriate. To test association within categories (e.g., high versus low), Chi-Square analysis was conducted on two Dalhousie variables: adult response, and people involved in pain event. Age effects (3 vs 4 vs 5-year-olds) were compared using one-way ANOVA; sex effects (Male vs Female) were compared using independent t-tests. Due to high levels of missing data within the day-care, the FPS-R and the Dalhousie duration of social response were compared only in the home-based conditions; using independent t-tests. Statistical significance for all tests was set at $\alpha$ level of $\mathrm{p}<.05$. Open-ended survey responses were examined independently and agreed upon by two researchers (GOS; LC), to identify common themes including best or worst elements of participation, or suggestions for improving the study design. 


\section{Results}

Participants

[INSERT TABLE 1 HERE]

Twelve families participated in the home-based recordings. As one family had two participating children, the total number of children was 13 , and 17 parents (12 mothers; 5 fathers). Families were divided equally between the two recording methodologies: ResearcherPresent-Home $(\mathrm{N}=6)$; Researcher-Not-Present-Home $(\mathrm{N}=6)$. These figures were suitable for a pilot study, based on previous recommendations (Hertzog, 2008). Average parental age was 38 years $(\mathrm{SD}=3.97)$. Most parents were married (94.4\%) and 10 families (83\%) had more than one child ( $M=2.1$ children; range: 1-4 children). There were 14 pain events observed from 12 recordings $(M=1.16$ per home). Pain events occurred approximately twice as often in the researcher-not-present condition $(\mathrm{N}=9)$ compared to the researcher-present condition $(\mathrm{N}=5)$; $\mathrm{t}(11)=1.82, \mathrm{p}=.049$.

Within the day-care, 33 children attended the day-care on at least one test date; one parent of a child attending on a test date opted out of the study, leaving a sample of 32 children. 44 pain events were observed, involving 17 of the 32 children (53\%) (Table 1). This echoes previously-reported figures (58\%; von Baeyer et al., 1998), though lower than the $81 \%$ reported in an observation of pain events within play activity centres (Noel et al., 2018).

\section{Researchers}

As recruitment had proven difficult in similar studies, four researchers were enlisted to complete observations, to ensure availability for participants. All were trained to code the Dalhousie scale by the PI, until a satisfactory level of agreement was reached. The four researchers did not overlap between locations: within the home, two researchers attended observations individually, to avoid unnecessary intrusion. Within the day-care, two other 
researchers initially coded events together, and once a satisfactory level of agreement was reached, only one researcher coded events at any given time. The PI and researchers independently scored the home-recording videos, to provide validity and inter-rater reliability checks. Agreement was generally high, aside from items relying on personal interpretation (e.g., distress intensity), as reported previously (Noel et al., 2018; von Baeyer et al., 1998).

\section{Settings}

Some logistical differences between the home and the day-care required adjustments: parents were not present in the day-care, so parental reactions could not be observed; instead, reactions from day-care staff were observed. The use of video-recording within the day-care was not possible: while parents consented to allow their child to be observed, not all consented to video-recording; thus, data collection in the day-care relied on the completion of the Dalhousie pain scale (Fearon et al., 1996) and the FPS-R (Hicks et al., 2001), to allow as many children as possible from the Kindergarten to participate. These changes ensured that study procedures were similar enough between the home and day-care settings to allow feasibility testing of the video-recording methodologies against traditional data collection methods in the day-care observations (Fearon et al., 1996).

As the Dalhousie scale was used in all three methodologies, it offers insight into how pain experience might vary with each observation type. The analyses presented contain the core items which were assessed in all locations and were relevant to the focus of this study (to determine feasibility of home versus day-care observation); thus, some items which are not likely to be affected by the different methodologies have not been reported; e.g., 'Bodily location of injury', 'Cause of injury', etc.

\section{Does observation type influence child behaviours during pain events?}

Following a pain event, children across all three conditions appeared to favour 'helpseeking' (36/58) or 'neutral' behaviours (19/58); thus, observation type did not influence type 
of response: $F(2,55)=.227, \mathrm{p}>.05, \eta^{2}=.008$. Within the home, mean duration of child responses was significantly increased for Researcher Present Home ( $M=8.3$ secs) compared to Researcher Not Present $(\mathrm{M}=1.67 \mathrm{secs}), \mathrm{t}(12)=-.2 .24, \mathrm{p}=.04, \mathrm{~d}=1.21$ (Duration of social responses was not assessed in the day-care).

Intensity of child distress (e.g., screaming, crying) was significantly influenced by observation type: Researcher Present Home (M=4.4; $\mathrm{SD}=.89)$, Researcher Not Present Home $(\mathrm{M}=2.78 ; \mathrm{SD}=.97)$, and Researcher Day-care $(\mathrm{M}=1.46 ; \mathrm{SD}=1.32), F(2,55)=15.06, \mathrm{p}=.001$, $\eta^{2}=.35$. Post-hoc (Fisher's LSD) tests confirmed that child distress was significantly lower in Researcher-Day-care observations than Researcher-Present-Home ( $\mathrm{p}=.00)$ or Researcher-NotPresent-Home $(\mathrm{p}=.005)$. Both home-recording conditions differed significantly from each other $(\mathrm{p}=.023)$, with more distress observed when researchers were present. Distress lasted, on average, 9.2 seconds ( $\mathrm{SD}=5.07$; range: 1-15 secs) for Researcher-Present-Home, 8.44 seconds ( $\mathrm{SD}=8.49$; range: 3-30 secs) for Researcher-Not-Present-Home, and 25.45 seconds for Researcher-Day-care ( $\mathrm{SD}=44.38$; range: 5-80 seconds). Despite duration of distress varying greatly, differences were not significant, $F(2,55)=.96, \mathrm{p}>.05, \eta^{2}=.034$.

Observation type significantly affected the child's level of personal control (e.g., how much control they had over their own behaviour); $F(2,55)=30.82, \mathrm{p}<.0001, \eta^{2}=.53$. Post-hoc (Fisher's LSD) tests revealed that children in Researcher-Day-care observations had lower control $(\mathrm{M}=4.16, \mathrm{SD}=1.08)$ than children in Researcher-Present-Home $(\mathrm{M}=1.80, \mathrm{SD}=.84)$, and Researcher-Not-Present-Home observations $(\mathrm{M}=1.67, \mathrm{SD}=.71) ; \mathrm{p}=.000$. Furthermore, within the home, children demonstrated lower control when experiencing pain events with their parent present, regardless of how many other observers were present (i.e., siblings and/or a researcher); $\mathrm{t}(12)=2.27, \mathrm{p}=.043, \mathrm{~d}=1.35$.

\section{Does observation type influence adult responses to pain?}


Observation type did not alter adult responses to pain events: Adults in all three conditions favoured comforting behaviours (physical or verbal comfort) over other behaviours, $\chi^{2}(10,58)=26.32, p=.003, V=.48$. In all settings, adults responded similarly: adults in the home favoured physical comfort (9/14), verbal comfort (2/14), distraction (1/14), first aid (1/14), regardless of researcher presence or absence; $\mathrm{p}>.05, \mathrm{~d}=.98$. Adults in the day-care favoured physical comfort (27/44) regardless of whether the child was seeking help, followed by distraction (8/44), conflict resolution (8/44), and verbal comfort (1/44). As almost all adults favoured physical comfort, this category was further assessed using Chi Square analysis, to explore whether adult responses corresponded to child distress: Adults favoured physical comfort more often if the child's distress was particularly intense and prolonged; $\chi^{2}$ $(50,58)=68.23, \mathrm{p}=.044, \mathrm{~V}=.61$ ("High" distress represented the child being rated as “Sobbing”/option 3 or above on Distress Intensity; or if Distress Duration lasted 8 seconds or longer, based on Fearon et al., 1996). Though adults appeared to respond more frequently if a child actively sought their help than if a child was withdrawn or neutral, this was not significant: $\mathrm{p}>.05, \eta^{2}=.054$.

\section{Does observation type influence pain estimates?}

Observation type significantly affected pain estimates. Child estimates on the FPS-R were lower in Researcher-Present-Home observations $(\mathrm{M}=4.00, \mathrm{SD}=.00)$ than in ResearcherNot-Present-Home observations $(\mathrm{M}=7.80, \mathrm{SD}=2.68) ; \mathrm{t}(14)=3.17, \mathrm{p}=.03, \mathrm{~d}=1.87$. Though parents tended to give lower FPS-R estimates for their child's pain $(\mathrm{M}=3.83, \mathrm{SD}=2.57)$, compared to the child's own estimates $(\mathrm{M}=6.71, \mathrm{SD}=2.87)$, their ratings did not significantly differ; $\mathrm{p}=.057, \mathrm{~d}=1.05$. In Researcher-Day-care observations, researchers encountered difficulties administering the FPS-R following pain events, as the children were not interested in completing it, or said they "did not know" which face applied best. As the FPS-R was used successfully in only 3 of 44 events, these results were not analysed, due to missing data. 
Finally, observation type influenced researcher estimates of pain severity: ResearcherPresent-Home $(\mathrm{M}=1.40, \mathrm{SD}=.55 ; \mathrm{N}=5)$; Researcher-Not-Present-Home $(\mathrm{M}=.33, \mathrm{SD}=.50$, $\mathrm{N}=9)$; day-care $(\mathrm{M}=.89, \mathrm{SD}=.62, \mathrm{~N}=44) ; F(2,55)=5.56, \mathrm{p}=.006, \eta^{2}=.17$. Post-hoc (Fisher's LSD) tests revealed that pain estimates in the Researcher-Not-Present-Home observations were significantly lower than either Researcher-Present-Home ( $\mathrm{p}=.002)$ or Researcher-Day-care estimates $(p=.014)$; these did not differ from each other $(p>.05)$.

\section{Influence of other factors on behavioural responses}

\section{Location}

The Location of event Dalhousie item was cross-checked with the video-recordings. As parents in both home conditions had been instructed to move the cameras when the child moved to a new space, both indoor and outdoor spaces were recorded. The observation type strongly influenced the location of pain events, $F(2,55)=16.22, p=.001, \eta^{2}=.37$ : Significantly more outdoor pain events occurred in Researcher-Day-care observations than either ResearcherPresent-Home $(p=.001)$ or Researcher-Not-Present-Home $(p=.001)$ observations. In all observation conditions, children were more likely to favour 'help-seeking', $t(56)=2.15, \mathrm{p}=.036$, $\mathrm{d}=.57$; or 'neutral' behaviours while outdoors, $\mathrm{t}(56)=-2.01, \mathrm{p}=.049, \mathrm{~d}=.54$; and children playing outdoors demonstrated lower control than children indoors; $t(56)=3.07, \mathrm{p}=.005, \mathrm{~d}=.79$. However, being outdoors did not have influence the child's distress, nor were there any differences in responses from caregivers while outdoors; all p>.05.

People involved in pain event

Within both home-observation conditions, the presence of additional people increased the likelihood of further pain events occurring later in the session; $\chi^{2}(4, \mathrm{~N}=13)=9.75, \mathrm{p}=.045$, $\mathrm{V}=.61$. The increased number of people also contributed to more intense displays of distress; $\chi^{2}(12, \mathrm{~N}=13)=24.81, \mathrm{p}=.016, \mathrm{~V}=.77$. These effects were not seen in the day-care. Age and sex effects 
There were limited sex effects: in all conditions, girls displayed higher personal control prior to pain events than boys; $\mathrm{t}(56)=2.14, \mathrm{p}=.036, \mathrm{~d}=.57$; and girls were more likely to be playing alone at the time of pain events (23/38), while boys were more likely to get hurt while playing with others $(14 / 20) ; \chi^{2}(1, \mathrm{~N}=58)=4.88, \mathrm{p}=.027, \mathrm{~V}=.29$.

There were no age or sex effects for distress; social response; adult response; location of pain events; or researcher pain ratings.

\section{Post-participation evaluation survey}

\section{[INSERT TABLE 2 HERE]}

As this study intended to determine the feasibility of home-recording methodologies, all participating parents were invited to complete an anonymous survey to evaluate whether the methodologies used in the current study were acceptable, or could be improved for future use (Appendix). If both parents participated, only one survey was completed, representing the views of the family. The Researcher-Present-Home and Researcher-Not-Present-Home methodologies were both considered acceptable to parents and produced similar outcomes (Table 2). Some differences emerged based on researcher presence: Parents rated their participation as 'Very positive' more often in the Researcher-Present-Home condition; $\mathrm{t}(10)=3.30, \mathrm{p}=.008, \mathrm{~V}=.78(\mathrm{Q} 1)$. Parents also gave higher ratings of the researcher's influence on their experience in the Researcher-Present-Home condition; $\mathrm{t}(8)=3.80, \mathrm{p}=.005, \mathrm{~V}=.76(\mathrm{Q} 8)$. While parents tended to rate participation as 'intrusive' in the Researcher-Not-Present-Home condition (Q5), this was not significant, $\mathrm{p}=.054, \mathrm{~V}=.81$. It was confirmed that researcher presence impacted parent behaviour; $\mathrm{r}=.677, \mathrm{p}=.022, \mathrm{~V}=.82$. Regarding the video-recording, the open-ended responses revealed that parents in both conditions felt uncomfortable at being filmed, stating it disrupted their own routine; e.g., 'I didn't do [household tasks] as I felt I needed to be ready to record things or intervene if he got hurt'; however, parents felt their child's behaviour did not change with the presence of cameras. Parent opinions about the length 
of recording varied: 'Even though it was long, it wasn't intrusive'; 'The observation was just right. 3 hours was perfect'; 'Length of filming should be longer to increase possibility of experiencing pain'. Others noted difficulties with keeping their child within range of the cameras: 'Keeping the kids within two rooms was difficult'; 'Wearable cameras would have been better'. If pain events did not occur, parents suggested methods that might increase the frequency of pain events: 'I wonder [if] this work better in a play centre/playground, where there would be greater likelihood of a fall/bang'.

\section{Discussion}

Childhood pain experiences, and especially 'everyday' pains, allow children to learn pain management skills from those in their social environment. However, pain research in 'everyday' settings is still lacking (Noel et al., 2018). This exploratory study intended to assess whether the video-recording of observations during 'everyday' painful experiences presents a viable methodology for conducting naturalistic paediatric pain research, and whether familial behaviour is altered when being observed by recording equipment and/or a researcher. Importantly, while parents felt that video-cameras within the family home influenced their own behaviour, they reported no such influences on their child's behaviour.

The survey findings confirmed that the recording methodologies were both acceptable to parents and provided valuable insight into the impact of slight differences in study set-up (e.g., researcher presence or absence). The behaviour of an observer can impact on the actor and be impacted in return (Cook \& Kenny, 2005); this potentially reduced the viability of recording the natural routine of families. While parents reported their study experiences as being more positive in the Researcher-Present-Home condition, researcher presence unduly influenced typical behaviour within the home: influencing the number of pain incidents that children experienced, the pain estimates given by children, the intensity of child distress, and 
the duration of social behaviours, compared to when families were video-recorded without a researcher present. It is possible that children behaved more cautiously than usual around the researcher, and that in their absence, children may have felt more relaxed, engaging in more boisterous play, and more opportunities for pain events. This was reflected in the ResearcherPresent-Day-care observations, where the children were surrounded by peers, and were used to having strangers present as the Kindergarten was affiliated with University research centres. As video-recording within the day-care centre was not possible, we cannot confirm if child behaviour would differ had there been cameras present instead of researchers.

Notably, the Researcher-Present-Home condition affected the researcher's own ability to objectively estimate child pain: 'perceived hurt' scores were significantly lower in the Researcher-Not-Present-Home (i.e., completed the scale during video playback), and Researcher-Present-Day-Care conditions. It may be that researchers present within the homewho had just presented the Revised Faces Pain Scale (FPS-R) to the child - were aware of the child's ratings of the pain, and this influenced their own pain estimations, while researchers in the other two conditions were not influenced by this. Alternatively, researchers within the home were able to see the child's facial expressions more closely which may have influenced their pain estimations compared to researchers scoring the video-tapes or observing in the day-care. As researchers in the day-care typically observed from a greater distance than researchers in the home-based observations, they might not have seen the child's facial expressions clearly. Facial expression provide a considerable influence on pain estimation; hence different levels of access to facial expressions could explain the variation of pain estimates across settings (Hadjistavropoulos et al., 2011; von Baeyer et al., 1998).

In comparing the innovative home-based observations to the established day-care observations, several differences must be considered: pain events were far more frequent in the day-care (2.93 events per hour) than within the home ( 0.39 events per hour), although the 
home-based pain events occurred at similar rates from previous day-care studies (i.e., one event per 3 hours) (Fearon et al., 1996; von Baeyer et al., 1998). Noel et al reported a similar rate of pain events to our day-care observations (approximately three per hour) in their observations of everyday pain events in a play activity centre (Noel et al., 2018). Furthermore, while the Dalhousie scale was used by all observers to assess the pain event immediately after it had happened, the context of the settings was different: parents were present in the home to provide support to their child after pain events, but not present in the day-care, leaving staff-child interactions as the primary source of communication during pain events. This made for an interesting comparison with how children managed pain in different settings and in the presence of different caregivers, but it does limit our ability to compare this outcome equally. In general, child behaviour within the home was consistent with behaviours within the daycare suggesting that the presence of video-cameras was not a notable distractor from the child's "everyday" experience of pain. However, certain pain-related behaviours were different between the home and the day-care centre; e.g., intensity of distress, and the child's personal control over their behaviour were both lower in the day-care than in the home. Previous daycare studies on everyday pain in older children similarly reported that the majority of pain incidents were of low severity and caused low levels of distress (Fearon et al., 1996; von Baeyer et al., 1998). Even young children might be more reluctant to express pain in front of peers than parents (Craig, 2009; Deyo, Prkachin, \& Mercer, 2004; Larochette, Chambers, \& Craig, 2006; Zeman \& Garber, 1996), as a result of social strictures such as avoiding embarrassment in front of peers, worrying their friends, or disrupting playtime. As other behaviours were consistent within the conditions, the presence of peers in the day-care may have inhibited the children from displaying distress, contributing to the notable difference from children within the home. The different observation types in this study were useful for demonstrating subtle 
differences in the child's response to pain in a group setting, compared to when the child experienced the pain event at home.

While the Researcher-Day-care environment was more efficient in capturing larger numbers of everyday pain events, it had drawbacks: video-recording was impossible to use, given data protection considerations, and the logistical issues of moving the equipment to keep the children within a close-enough distance to code effectively. Use of the FPS-R within the day-care was challenging and only administered sporadically: researchers found it difficult to approach the child once they had relaxed, as children were often uninterested in responding or said they didn't know which pain rating applied to them. As one of the stalwart scales for paediatric self-report, the FPS-R was chosen to fit within the existing body of work; however, newer instruments considered more appropriate for younger children have since been identified (von Baeyer, 2017), and this may resolve some of the challenges faced in this study. Only one previous observational study attempted video-recording, but the recordings were of too-low quality to code (Noel et al., 2018). The increased burden directly observing multiple children in the day-care centre, and the associated increase in activity level, prevented us from asking day-care staff for deeper insight into individual pain events. In contrast, the home-based video observations allowed for rich interpretation of each pain event, as the video-recordings captured contextual details to supplement the pain scales completed by the parents and children. The continued development of methodologies specifically for use in naturalistic observations (or refinement of existing procedures) may resolve these issues. The Dalhousie Everyday Pain Scale, used within the current study, has recently been adapted to include objective parental responses to pain, and can be used in the home (Noel et al., 2018); future studies could benefit from similar efforts to improve existing observation tools.

Naturalistic observation of children is not without some practical issues, as reported previously (Campos et al., 2009; Fearon et al., 1996; Gilbert-MacLeod et al., 2000; Noel et al., 
2018). The post-participation survey revealed that the home-observation conditions suffered from equipment limitations: parents were loaned two cameras, which meant restricting the child to only two rooms during recording, or moving and re-setting the cameras each time the child entered a new room. The parents felt that these restrictions impacted their behaviour, affecting interactions with their child and the estimates they gave for pain events. Parents still regarded their participation as positive, so the intrusion imposed by the cameras was not a detrimental factor; however, such restrictions should be considered when designing studies involving video-recording. Additional equipment, or less cumbersome equipment (e.g., wearable cameras) could allow families to move freely within the house and contribute to the naturalistic representation of their normal routine. Another commonly-reported issue from the post-participation survey concerned the time-commitment for participation: The lengthy sessions proved to be a detractor when recruiting families and posed logistical issues for researchers attending the recordings. In each session, considerable time was given to parents for completing various psychometric measures, along with consent and assent forms and the evaluation survey. While participating families mostly found this experience (and the time commitment) to be acceptable, these families were already enrolled in the study and thus, more likely to report positive outcomes. Considering the difficulties associated with recruitment, the acceptability of the methodologies by the general public may be lower than that reported here, and recruitment for similar studies may also face similar challenges. To reduce the time commitment and make participation more attractive, it might be less burdensome if measures were completed prior to the session (by mailing the forms in advance), and for any evaluation surveys to be returned afterwards. While the researchers within the home reported no difficulties sustaining attention during the observations, there were periods with little activity during which fatigue or distraction could set in; we attempted to counteract this by alternating which researcher attended each session, and by scoring the videos afterwards, to ensure the 
scores remained consistent with the in-person coding. The day-care centre sessions were attended by pairs of researchers, so such issues were avoided; however, this was not practical in the home without disrupting the environment.

Within paediatric pain literature, there is a disproportionate representation of pain within clinical contexts or of clinical relevance: they are often easier to report, and their controllable context and specified time of onset make them 'methodologically cleaner' than everyday pains (Fearon et al., 1996). Everyday pains are spontaneous and occur randomly, if at all (von Baeyer et al., 1998), which often requires a trade-off in external validity (GilbertMacLeod et al., 2000). We found several instances where pain events did not occur at all within the home, reducing the efficiency of a three-hour recording period. In such situations, it may be possible to supplement observational data by asking parent and child to discuss a recent pain experience; a similar approach was recently established for clinical pains, such as experimental, procedural, and post-surgical pains (Noel, Pavlova et al., 2017). This technique could be adapted for use with everyday pain experiences; for example, a brief discussion of how the child felt about a pain such as a tummy-ache or falling over. Such approaches could facilitate recording everyday pains and increase study in this area.

In summary, all three methods of observation captured broadly similar behaviours by the children. Minor influences resulted from the presence of researchers but not from the presence of cameras, which indicates the feasibility of using video-recording to conduct naturalistic observational research within family home environments, at least equivalent to currently-established direct observation techniques. These methodologies provided a complementary outlook on how children experience "everyday" pain events: the videorecorded home observations provided clearer insight into the unique relationship between parent and child, and the shared interactions during a painful event; while the day-care observations allowed insight into how children utilise pain-management skills while with 
peers, and the potential influence of peers over their experience of pain. Subsequent paediatric research efforts should continue examining everyday pain experiences, to supplement the wealth of research on clinically-presented pains and strengthen our understanding of the social context of pain in childhood. This exploratory study has confirmed that paediatric research is feasible beyond clinical or experimental settings, and the continued development of new methodologies, or the novel combination of methodologies suitable for this research focus, are crucial endeavours to significantly improve the quality of studies being conducted and the options available for future research.

\section{Limitations}

The participants of the home-study were recruited from day-care centres and playgroups located within Galway, Ireland. The sample was quite small ( $\mathrm{N}=13$ children) and may have been overly homogenous, reducing the ability to draw firm conclusions regarding behaviours within each setting. The children in the day-care study were enrolled in one university nursery in Stirling, Scotland. As a university research facility, the families lived locally, which may have affected the diversity of the sample, and findings may not translate to areas with a more culturally-diverse population. The sample size was within recommended limits for pilot studies (Hertzog, 2008), and allowed us to explore the feasibility of recruiting for and conducting at-home video-recording, and to identify logistical issues which might impact its effectiveness. For instance, having access to only two video-cameras may have impacted the quality of the data, as parents had to either restrict their child within the rooms with cameras, or move the cameras whenever the child left the designated rooms. Despite this, the technique proved effective: all pain events within the home were either captured on video or through audio (i.e., where the child was just out of frame, but could clearly be heard, which was sufficient for coding the relevant variables), and no pain data was lost. Future studies may 
benefit from additional equipment, to allow the children to move freely about their home, and capture more natural experiences.

\section{Acknowledgements}

This study was facilitated by funding support from the 2015 IASP Early Career Research Grant, awarded to Dr Caes, and the Hardiman Scholarship at NUI Galway, Ireland, awarded to Ms O'Sullivan. Thanks are given to Emer Gormley for her assistance with data collection in the homes; to the University of Stirling Kindergarten staff Federica Caruso and Sarah Thorburn, and to Caitlin Rennie, Ruta Zemcugovaite and Sarah Dempsey for their assistance with data collection in the day-care centre. Our most sincere acknowledgment are given to the families who participated in these research studies.

\section{Declaration of interest statement}

The authors have no conflicts of interest to declare.

\section{References}

Birnie, K. A., Chambers, C. T., Taddio, A., McMurtry, C. M., Noel, M., Pillai Riddell, R., \& Shah, V. (2015). Psychological Interventions for Vaccine Injections in Children and Adolescents: Systematic Review of Randomized and Quasi-Randomized Controlled Trials. The Clinical Journal of Pain, 31(10), S72-S89.

Blount, R. L., Bachanas, P. J., Powers, S. W., Cotter, M. C., Franklin, A., Chaplin, W., . . Blount, S. D. (1992). Training children to cope and parents to coach them during routine immunizations: Effects on child, parent and staff behaviors. Behavior Therapy, 23(4), 689-705.

Blount, R. L., Devine, K. A., Cheng, P. S., Simons, L. E., \& Hayutin, L. (2008). The Impact of Adult Behaviors and Vocalizations on Infant Distress during Immunizations. Journal of Pediatric Psychology, 33(10), 1163-1174. doi:10.1093/jpepsy/jsn030

Boerner, K. E. (2017). How does watching a parent in pain impact children's own pain experiences? Retrieved from https://www.bodyinmind.org/parent-pain-child-pain/

Boerner, K. E., Chambers, C. T., McGrath, P. J., LoLordo, V., \& Uher, R. (2017). The Effect of Parental Modeling on Child Pain Responses: The Role of Parent and Child Sex. The Journal of Pain, 18(6), 702-715.

Brown, E. A., De Young, A., Kimble, R., \& Kenardy, J. (2018). Review of a Parent's Influence on Pediatric Procedural Distress and Recovery. Clinical Child and Family Psychology Review, 21(1), 1-22. 
Caes, L., Vervoort, T., Eccleston, C., \& Goubert, L. (2012). Parents who catastrophize about their child's pain prioritize attempts to control pain. Pain, 153(8), 1695-1701. doi:10.1016/j.pain.2012.04.028

Caes, L., Vervoort, T., Eccleston, C., Vandenhende, M., \& Goubert, L. (2011). Parental catastrophizing about child's pain and its relationship with activity restriction: The mediating role of parental distress. Pain, 152(1), 212-222. doi:10.1016/j.pain.2010.10.037

Campos, B., Graesch, A. P., Repetti, R., Bradbury, T., \& Ochs, E. (2009). Opportunity for interaction? A naturalistic observation study of dual-earner families after work and school. Journal of Family Psychology, 23(6), 798-807. doi:10.1037/a0015824

Chambers, C. T., Taddio, A., Uman, L. S., \& McMurtry, C. M. (2009). Psychological interventions for reducing pain and distress during routine childhood immunizations: A systematic review. Clinical Therapeutics, 31, S77-S103. doi:10.1016/j.clinthera.2009.07.023

Chitkara, D. K., Rawat, D. J., \& Talley, N. J. (2005). The epidemiology of childhood recurrent abdominal pain in Western countries: a systematic review. The American Journal of Gastroenterology, 100(8), 1868.

Christensen, L. B. (2007). Experimental methodology (10th ed. ed.): Boston (Mass.) : Pearson/Allyn and Bacon.

Claar, R. L., Simons, L. E., \& Logan, D. E. (2008). Parental response to children's pain: the moderating impact of children's emotional distress on symptoms and disability. Pain, 138(1), 172-179.

Cook, W., \& Kenny, D. (2005). The Actor-Partner Interdependence Model: A model of bidirectional effects in developmental studies. International Journal of Behavioral Development, 29(2), 101-109. doi:10.1080/01650250444000405

Craig, K. D. (2009). The social communication model of pain. Canadian Psychology, 50(1), 22-32.

Deyo, K. S., Prkachin, K. M., \& Mercer, S. R. (2004). Development of sensitivity to facial expression of pain. Pain, 107(1-2), 16-21.

Emmott, A. S., West, N., Zhou, G., Dunsmuir, D., Montgomery, C. J., Lauder, G. R., \& von Baeyer, C. L. (2017). Validity of Simplified Versus Standard Self-Report Measures of Pain Intensity in Preschool-Aged Children Undergoing Venipuncture. The Journal of Pain, 18(5), 564-573. doi:10.1016/j.jpain.2016.12.015

Fearon, I., McGrath, J. P., \& Achat, H. (1996). 'Booboos': the study of everyday pain among young children. Pain, 68(1), 55-62. doi:10.1016/s0304-3959(96)03200-9

Gilbert-MacLeod, C. A., Craig, K. D., Rocha, E. M., \& Mathias, M. D. (2000). Everyday Pain Responses in Children With and Without Developmental Delays. Journal of Pediatric Psychology, 25(5), 301-308. doi:10.1093/jpepsy/25.5.301

Goubert, L., Vervoort, T., Sullivan, M. J. L., Verhoeven, K., \& Crombez, G. (2008). Parental Emotional Responses to Their Child's Pain: The Role of Dispositional Empathy and Catastrophizing About Their Child's Pain. The Journal of Pain, 9(3), 272-279. doi:10.1016/j.jpain.2007.11.006

Goubert, L., Vlaeyen, J. W. S., Crombez, G., \& Craig, K. D. (2011). Learning About Pain From Others: An Observational Learning Account. The Journal of Pain, 12(2), 167-174. doi:10.1016/j.jpain.2010.10.001

Hadjistavropoulos, T., Craig, K. D., Duck, S., Cano, A., Goubert, L., Jackson, P. L., . . Fitzgerald, T. D. (2011). A biopsychosocial formulation of pain communication. Psychological Bulletin, 137(6), 910-939. doi:10.1037/a0023876

Hertzog, M. A. (2008). Considerations in determining sample size for pilot studies. Research in nursing \& health, 31(2), 180-191.

Hicks, C. L., von Baeyer, C. L., Spafford, P. A., van Korlaar, I., \& Goodenough, B. (2001). The Faces Pain Scale - Revised: toward a common metric in pediatric pain measurement. Pain, 93(2), 173-183. doi:10.1016/s0304-3959(01)00314-1

HSE. (2016). "Baby and Childhood Immunisation". Retrieved from http://www.hse.ie/eng/health/Immunisation/pubinfo/newschedule/ 
Kleiber, C., \& Harper, D. C. (1999). Effects of Distraction on Children's Pain and Distress During Medical Procedures: A Meta-Analysis. Nursing Research, 48(1), 44-49. doi:10.1097/00006199-199901000-00007

Kochanska, G., \& Aksan, N. (2004). Development of mutual responsiveness between parents and their young children. Child development, 75(6), 1657-1676.

Larochette, A. C., Chambers, C. T., \& Craig, K. D. (2006). Genuine, suppressed and faked facial expressions of pain in children. Pain, 126(1-3), 64-71.

Lisi, D., Campbell, L., Riddell, R. P., Garfield, H., \& Greenberg, S. (2013). Naturalistic parental pain management during immunizations during the first year of life: Observational norms from the OUCH cohort. Pain, 154(8), 1245-1253. doi:10.1016/j.pain.2013.03.036

MacLaren, J. E., \& Cohen, L. L. (2005). A comparison of distraction strategies for venipuncture distress in children. Journal of Pediatric Psychology, 30, 387-396.

Manimala, M. R., Blount, R. L., \& Cohen, L. L. (2000). The effects of parental reassurance versus distraction on child distress and coping during immunizations. Children's Health Care, 29(3), 161-177.

Morsbach, S. K., \& Prinz, R. J. (2006). Understanding and improving the validity of self-report of parenting. Clinical Child and Family Psychology Review, 9(1), 1-21.

NHS. (2016). "When to have vaccinations". Retrieved from https://www.nhs.uk/Conditions/vaccinations/Pages/vaccination-schedule-age-checklist.aspx

Noel, M., Chambers, C. T., Parker, J. A., Aubrey, K., Tutelman, P. R., Morrongiello, B., . . v von Baeyer, C. L. (2018). Boo-boos as the building blocks of pain expression: an observational examination of parental responses to everyday pain in toddlers. Canadian Journal of Pain, 2(1), 74-86. doi:10.1080/24740527.2018.1442677

Noel, M., Pavlova, M., McCallum, L., \& Vinall, J. (2017). Remembering the hurt of childhood: A psychological review and call for future research. Canadian Psychology, 58(1), 58-68.

Palermo, T. M., Valrie, C. R., \& Karlson, C. W. (2014). Family and parent influences on pediatric chronic pain: A developmental perspective. American Psychologist, 69(2), 142-152. doi:10.1037/a0035216

Perquin, C. W., Hazebroek-Kampschreur, A. A. J. M., Hunfeld, J. A. M., Bohnen, A. M., van SuijlekomSmit, L. W. A., Passchier, J., \& van der Wouden, J. C. (2000). Pain in children and adolescents: a common experience. Pain, 87(1), 51-58. doi:10.1016/s0304-3959(00)00269-4

Pillai Riddell, R., Taddio, A., McMurtry, C. M., Chambers, C., Shah, V., \& Noel, M. (2015). Psychological Interventions for Vaccine Injections in Young Children 0 to 3 Years. The Clinical Journal of Pain, 31, S64-S71. doi:10.1097/ajp.0000000000000279

Tomlinson, D., von Baeyer, C. L., Stinson, J. N., \& Sung, L. (2010). A systematic review of faces scales for the self-report of pain intensity in children. PEDIATRICS, 126, e1-e31.

von Baeyer, C. L., Baskerville, S., \& McGrath, P. J. (1998). Everyday pain in three- to five-year-old children in day care. Pain Res Manag., 3(2), 111-116.

von Baeyer, C. L., Jaaniste, T., Vo, H. L., Brunsdon, G., Lao, H. C., \& Champion, G. D. (2017). Systematic review of self-report measures of pain intensity in 3-and 4-year-old children: bridging a period of rapid cognitive development. The Journal of Pain, 18(9), 1017-1026.

von Baeyer, C. L., \& Spagrud, L. J. (2007). Systematic review of observational (behavioral) measures of pain for children and adolescents aged 3 to 18 years. Pain, 127(1), 140-150. doi:10.1016/j.pain.2006.08.014

Weiss, K. E., Dahlquist, L. M., \& Wohlheiter, K. (2011). The effects of interactive and passive distraction on cold pressor pain in preschool-aged children. Journal of Pediatric Psychology, 36(7), 816-826.

Zeman, J., \& Garber, J. (1996). Display rules for anger, sadness, and pain: It depends on who is watching. Child development, 67(3), 957-973. 


\section{Tables}

Table 1 - Demographic information for each condition

\begin{tabular}{|c|c|c|c|c|c|c|c|}
\hline Condition & $\begin{array}{l}\text { \# participating } \\
\text { children }\end{array}$ & $\begin{array}{l}\text { Age } \\
\text { (SD) } \\
\text { (mths) }\end{array}$ & $\begin{array}{l}\text { Age } \\
\text { range } \\
\text { (mths) }\end{array}$ & \# pain events & Sex & Location & $\begin{array}{l}\text { Pain } \\
\text { events } \\
\text { /hour }\end{array}$ \\
\hline Home & $\begin{array}{c}13 \\
(6 \mathrm{M} ; 7 \mathrm{~F})\end{array}$ & $\begin{array}{l}45.37 \\
(8.59)\end{array}$ & $37-68$ & 14 & $\begin{array}{l}4 / 14 \\
\text { Male } \\
(29 \%)\end{array}$ & $\begin{array}{c}\text { 0/14 } \\
\text { Outside } \\
(0 \%)\end{array}$ & 0.39 \\
\hline $\begin{array}{c}\text { Researcher } \\
\text { present }\end{array}$ & 6 & $\begin{array}{c}44.6 \\
(4.98)\end{array}$ & & 5 & $1 M ; 4 F$ & - & \\
\hline Not present & 7 & $\begin{array}{c}45.11 \\
(10.06)\end{array}$ & & 9 & $3 M ; 6 F$ & - & \\
\hline Day-care & $\begin{array}{c}32 \\
(25 \mathrm{M} ; 19 \mathrm{~F})\end{array}$ & $\begin{array}{c}48.4 \\
(6.46)\end{array}$ & $38-63$ & $\begin{array}{c}44 \\
(25 \mathrm{M} ; 19 \mathrm{~F})\end{array}$ & $\begin{array}{l}25 / 44 \\
\text { Male } \\
(57 \%)\end{array}$ & $\begin{array}{c}25 / 44 \\
\text { Outside } \\
\\
(57 \%)\end{array}$ & 2.93 \\
\hline
\end{tabular}


Table 2 - Home research participation survey responses, by condition

\begin{tabular}{|c|c|c|c|c|}
\hline Question & Range & $\begin{array}{l}\text { Researcher } \\
\text { (M; SD; N) }\end{array}$ & $\begin{array}{c}\text { No } \\
\text { researcher } \\
(\mathrm{M} ; \mathrm{SD} ; \mathrm{N})\end{array}$ & Sig. \\
\hline 1) Participation experience & $0-10$ & $\begin{array}{c}9.57 \\
(.79 ; N=7)\end{array}$ & $\begin{array}{c}7.00 \\
(1.87 ; N=5)\end{array}$ & $\begin{array}{c}t(10)=3.30 \\
p=.008\end{array}$ \\
\hline 4) Child acting the same as usual & $0-4$ & $\begin{array}{c}.50 \\
(.85 ; N=6)\end{array}$ & $\begin{array}{c}.50 \\
(1.00 ; \mathrm{N}=4)\end{array}$ & $\begin{array}{c}t(9)=-1.11 \\
p>.05\end{array}$ \\
\hline $\begin{array}{l}\text { 5) Did the observation } \\
\text { and/or recording feel } \\
\text { intrusive? }\end{array}$ & $0-10$ & $\begin{array}{c}2.00 \\
(1.92 ; \mathrm{N}=7)\end{array}$ & $\begin{array}{c}5.80 \\
(4.09 ; \mathrm{N}=5)\end{array}$ & $\begin{array}{c}t(10)=2.18 \\
p=.054\end{array}$ \\
\hline $\begin{array}{l}\text { 6) Were things different because you } \\
\text { were being videotaped? }\end{array}$ & $0-10$ & $\begin{array}{c}3.71 \\
(2.14 ; \mathrm{N}=7)\end{array}$ & $\begin{array}{c}5.80 \\
(1.92 ; N=5)\end{array}$ & $\begin{array}{c}t(10)=1.73 \\
p>.05\end{array}$ \\
\hline $\begin{array}{l}\text { 7) Did you feel comfortable with the } \\
\text { duration of the observation (i.e. } 3 \text { hours)? }\end{array}$ & $0-10$ & $\begin{array}{c}7.86 \\
(2.19 ; N=7)\end{array}$ & $\begin{array}{c}6.80 \\
(1.10 ; N=5)\end{array}$ & $\begin{array}{l}t(10)=.98 \\
p>.05\end{array}$ \\
\hline $\begin{array}{l}\text { 8) What influence did the researchers } \\
\text { have on your experience in this study? }\end{array}$ & $0-10$ & $\begin{array}{c}9.29 \\
(1.89 ; \mathrm{N}=7)\end{array}$ & $\begin{array}{c}5.00 \\
(.00 ; N=3)\end{array}$ & $\begin{array}{c}t(8)=3.80 \\
p=.005\end{array}$ \\
\hline
\end{tabular}

